\title{
THE INHIBITION OF HAEMOPHILUS INFLUENZAE BY CERTAIN AGAR AND PEPTONE PREPARATIONS
}

\author{
Nora M. Evans AND D. D. SMITH \\ Bacteriology Laboratory, The Prince of Wales Hospital, \\ Randwick, N.S.W., Australia
}

\begin{abstract}
A MEDIUM developed for nutritional studies of Haemophilus influenzae proved satisfactory for a period of about 2 years (Evans and Smith, 1972), but subsequently certain batches were found to be defective. The inoculum required to initiate growth increased from less than 10 cells to $10^{7}$, the colonies were of irregular size and microscopically many filamentous forms were evident. The constituents of both satisfactory and unsatisfactory media appeared to be identical, and preliminary investigations suggested that the duration and temperature of autoclaving might adversely affect the medium.

Inhibitory effects of media have been attributed to a number of agents including copper, colloidal sulphur, peroxides, fatty acids, certain amino acids and other substances (Burnet, 1925; Gordon and McLeod, 1926; O'Meara and Macsween, 1936; Ley and Mueller, 1946; Casman, 1947; Proom et al., 1950; Nieman, 1954; Woiwod, 1954; Traxler and Lankford, 1957; Dukes and Gardner, 1961). This paper describes an extension of earlier studies on proteose peptone as a basal medium for $\boldsymbol{H}$. influenzae and the value of dithionite and sodium oleate as additives to neutralise potential inhibitors.
\end{abstract}

\section{MATERIALS AND METHODS}

Media. Chocolate agar was prepared (Cruickshank, 1965) from Columbia Agar (Oxoid) with $7.5 \%$ horse blood. Proteose Peptone Agar for most experiments contained $2 \%$ Proteose

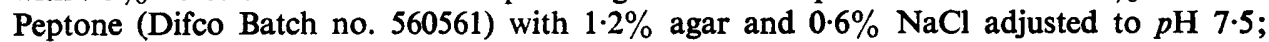
other proteose peptones used for comparison were Difco batch no. 542610, Oxoid no. 1994201 and BBL Myosate Peptone no. 809619. Agars used were Oxoid Agar no. 1, batch no. 355 7565, Oxoid Immuno-diffusion Agar and Difco Noble Agar.

Sterilisation. Agar and proteose peptone were autoclaved together in 20-ml amounts, or separately at double strength in 10-ml amounts, in Universal screw-capped containers.

Chemicals and growth factors. These were sterilised as stock solutions by means of a Swinnex $0.45-\mu$ Millipore Filter Unit and added to the molten proteose peptone agar at $56^{\circ} \mathrm{C}$. Haemin (Koch-Light), NAD ( $\beta$-diphosphopyridine nucleotide, Sigma Chemical Co. Ltd) and glucose (Univar, Ajax Chemicals Ltd, Australia) were added to all plates to give final concentrations of $20 \mu \mathrm{g}$ per $\mathrm{ml}, 1 \mu \mathrm{g}$ per $\mathrm{ml}$ and $2000 \mu \mathrm{g}$ per ml respectively. Sodium oleate (BDH Ltd) was used at a final concentration of $4 \mu \mathrm{g}$ per $\mathrm{ml}$. The reducing agents cysteine hydrochloride $(\mathrm{BDH})$, sodium dithionite $(\mathrm{BDH})$, sodium thioglycollate (Sigma), Cleland's reagent (Sigma) and glutathione (Sigma) were each incorporated in the medium at a final concentration of $100 \mu \mathrm{g}$ per ml. Other compounds, impregnated in 6-mm Whatman AA disks, were manganese dioxide, catalase, bovine serum albumen, yeast extract, nucleic acids, Casamino Acids, purines, Fildes' extract, horse serum and a vitamin mixture.

Organisms. A single laboratory strain of $H$. influenzae, type $b$ (strain West), isolated from cerebrospinal fluid, was initially used; 22 other strains were also used, six of which were type culture strains, nos. NCTC8467 (type $b$ ), NCTC8465 (type $a$ ), NCTC8469 (type $c$ ), NCTC8472 (type $e$ ), NCTC10479 (type $e$ ) and NCTC4560 (unencapsulated), and 16 strains, recently isolated from clinical material, of which four were encapsulated and of type $b$. All strains were identified by their requirement for both haemin and NAD, by means of a satellitism test (Evans and Smith, 1972); iridescent strains were examined for agglutination and capsular swelling with $H$. influenzae antisera types $a-f$ (Burroughs Wellcome).

Received 16 Aug. 1973; accepted 10 Oct. 1973.

J. MED. MICROBIOL.-VOL. 7 (1974) 
Inoculum. Organisms were grown on chocolate agar for 20 hours at $37^{\circ} \mathrm{C}$ in $5 \% \mathrm{CO}_{2}$ in air $(\mathrm{v} / \mathrm{v})$ and suspended in proteose peptone broth to give approximately $5 \times 10^{8}$ viable organisms per $\mathrm{ml}$. This suspension and three dilutions of it were seeded from a dropping pipette delivering $0.02 \mathrm{ml}$ on to the surface of each plate and on to control plates of chocolate agar, to give inocula of approximately $10^{7}, 10^{5}, 10^{3}$ and $10^{1}$ cells; each test was carried out in triplicate. In addition, a multiple inoculating device (Steers, Foltz and Graves, 1959) was employed for some of the experiments; this delivered the same inocula in volumes of $4 \mu$ l.

Incubation. Plates were incubated for 15 hours in an atmosphere of $5 \% \mathrm{CO}_{2}$ in air $(\mathrm{v} / \mathrm{v})$ at $37^{\circ} \mathrm{C}$. In some experiments, the air contained no added $\mathrm{CO}_{2}$.

Assessment of growth. The number and size of colonies grown on the medium sterilised at different temperatures was recorded and compared with those on chocolate agar and on proteose peptone agar sterilised at $116^{\circ} \mathrm{C}$ : colonies were measured with a micrometer eyepiece in a microscope fitted with a $\times 3$ objective.

Estimation of copper. A spectrophotometric method was used to determine the amount of copper in $12 \%$ aqueous solutions of the proteose peptones. Copper was liberated by a wet-ashing procedure and reacted with oxalyldihydrazide together with acetaldehyde in ammoniacal solution to give an intense blue-red colour (Beale and Croft, 1964).

\section{RESULTS}

\section{The effect of temperature on the growth of Haemophilus influenzae on proteose peptone agar}

The increasing inhibition of growth of a strain of $H$. influenzae type $b$ (strain West), resulting from the higher temperatures at which the medium was autoclaved, may be seen from the data in the table. The medium, heated at $116^{\circ} \mathrm{C}$ for $10 \mathrm{~min}$. and seeded with a $10^{-6}$ dilution of the standard suspension, yielded 5-15 colonies averaging $1.5 \mathrm{~mm}$ in diameter; after heating at $121^{\circ} \mathrm{C}$, the colony size and numbers were reduced, and after $126^{\circ} \mathrm{C}$ for 30 min. inhibition was complete. Another manifestation of the inhibitory effect, caused by heating the medium at the higher temperature, was the minimum inoculum required to initiate growth. On the medium heated at $116^{\circ} \mathrm{C}$, the standard inoculum of 5-15 viable units developed as colonies, but on media heated at $121^{\circ} \mathrm{C}$ and $126^{\circ} \mathrm{C}$, the minimum inocula required were $10^{5}$ and $10^{7}$ respectively. No improvement was obtained by increased incubation times of 24 or 36 hours.

The results referred to in the table were compiled from experiments in which cultures were incubated in an atmosphere of $5 \% \mathrm{CO}_{2}$ in air. In atmospheres of air without $\mathrm{CO}_{2}$, the colonies were smaller, $0.5-1.0 \mathrm{~mm}$ in diameter on the medium autoclaved at $116^{\circ} \mathrm{C}$; and they were minute, measuring $0.05 \mathrm{~mm}$ in diameter, on the medium heated at $126^{\circ} \mathrm{C}$. In neither case, however, was the colony count less than that on chocolate agar.

Although the medium autoclaved at $121^{\circ} \mathrm{C}$ or $126^{\circ} \mathrm{C}$ failed to yield any growth in an atmosphere of $5 \% \mathrm{CO}_{2}$ in air when inoculated with 5-15 cells, its capacity to sustain growth could be restored by the addition of sodium dithionite, sodium thioglycollate or Cleland's reagent (table). Other reducing agents incorporated in the agar were less effective, but around paper disks impregnated with cysteine hydrochloride, glutathione, or manganese dioxide growth of $H$. influenzae was evident on proteose peptone agar sterilised at $126^{\circ} \mathrm{C}$; there was no growth at a distance from the disks. A similar effect was obtained around disks containing saponin, Tween 80 , bovine albumen, horse serum or yeast extract, but not catalase. It was also observed that if plates of media that had been heated at $121^{\circ} \mathrm{C}$ or $126^{\circ} \mathrm{C}$ were stored in air for 24 hours at $37^{\circ} \mathrm{C}$ or for 7 days at $4^{\circ} \mathrm{C}$, growth from a small inoculum occurred without addition of a reducing agent.

In the experiments summarised in the table, the proteose peptone and the agar were autoclaved together; similar results were obtained however, when they were sterilised separately and when the experiments were repeated with another batch of Proteose Peptone (Difco batch no. 542610). 
Growth was not obtained from inocula of 5-15 viable units of a further 22 strains of $H$. influenzae on proteose peptone medium heated at $126^{\circ} \mathrm{C}$. However, when sodium dithionite was added, growth was comparable with that on control plates sterilised at $116^{\circ} \mathrm{C}$.

The Oxoid and BBL Proteose Peptone autoclaved at $116^{\circ} \mathrm{C}$ gave colonies of smaller size, but these media were less affected by increased temperatures of sterilisation. The BBL medium appeared the least sensitive to heat. As with the Difco peptone, sodium dithionite reversed the inhibition.

\section{The inhibitory effect of certain brands of agar on the growth of Haemophilus influenzae}

A number of agar preparations from different manufacturers were examined. Separate sterilisation of proteose peptone broth and agar at $116^{\circ} \mathrm{C}$ for $10 \mathrm{~min}$. revealed that a certain

TABLE

Effect of temperature and duration of autoclaving of Difco Proteose Peptone agar, with and without dithionite, on the growth of Haemophilus influenzae

\begin{tabular}{|c|c|c|c|c|}
\hline \multicolumn{3}{|c|}{ Preparation of medium } & \multirow{3}{*}{$\begin{array}{c}\text { Size of colonies } \dagger \\
(\mathrm{mm})\end{array}$} & \multirow{3}{*}{$\begin{array}{l}\text { Percentage of inoculum } \\
\text { forming colonies } \ddagger\end{array}$} \\
\hline \multicolumn{2}{|c|}{ sterilisation } & \multirow{2}{*}{$\begin{array}{l}\text { Addition of } \\
\text { dithionite* }^{*}\end{array}$} & & \\
\hline $\begin{array}{l}\text { temperature } \\
\left({ }^{\circ} \mathrm{C}\right)\end{array}$ & $\begin{array}{c}\text { time } \\
(\mathrm{min} .)\end{array}$ & & & \\
\hline 116 & 10 & - & 1.5 & 100 \\
\hline 121 & 30 & $\stackrel{+}{-}$ & $\begin{array}{c}1.5 \\
0.05-0.75\end{array}$ & $\begin{array}{r}100 \\
30\end{array}$ \\
\hline 126 & 30 & \pm & $0^{1 \cdot 5}$ & $\begin{array}{r}100 \\
0\end{array}$ \\
\hline & & + & 1.5 & 100 \\
\hline
\end{tabular}

$*-=$ Not added $++=$ added.

$\uparrow$ Cultures incubated for 15 hours in an atmosphere of $5 \% \mathrm{CO}_{2}$ in air $(\mathrm{v} / \mathrm{v})$.

$¥$ Number of colonies developing, expressed as a percentage of the number on control plates of chocolate agar. The inoculum was a $10^{-6}$ dilution of a standard suspension, and contained 5-15 colony-forming units.

batch of Oxoid Agar no. 1 (no. 3557565 ) was inhibitory. A minimum inoculum of $10^{3}$ cells was required, and the colonies that grew ranged from 0.05 to $1 \mathrm{~mm}$ in diameter; the number of colonies was reduced in comparison with those developing on chocolate agar. The inhibition caused by this agar was pronounced when the sterilisation temperature was reduced to $100^{\circ} \mathrm{C}$, but was eliminated by autoclaving the agar separately at $126^{\circ} \mathrm{C}$, by washing the agar in distilled water, by filtering the molten agar through paper pulp or a charcoal-block filter, or by adding $4.0 \mathrm{mg}$ per 1 of sodium oleate. The inhibitory effect of agar did not disappear on storage of the plates.

The inhibitory effect was demonstrated when the agar was taken from a freshly opened bottle, but not from bottles which had been opened for more than 4 weeks, and was observed with three bottles of the same batch. The other agars tested, Oxoid Ionagar no. 2 and Difco Noble Agar, were not inhibitory.

\section{Copper}

The copper content of the three brands and batches of Proteose Peptone were as follows: Difco batch no. 560561, 3.9 $\mu \mathrm{g}$ per g; Difco batch no. 542610, 10.3 $\mu \mathrm{g}$ per g; Oxoid batch no. $1994201,2 \cdot 0 \mu \mathrm{g}$ per $\mathrm{g}$; and BBL batch no. 809619, 9.5 $\mu \mathrm{g}$ per $\mathrm{g}$. 


\section{Discussion}

Changes occurring during the heating of media that affect the growth of bacteria are complex. Dubos (1930) found that peptone autoclaved under normal conditions and left at room temperature for $\mathbf{4 8}$ hours became inhibitory for pneumococci, especially when small inocula were used, but inhibition did not occur under reducing conditions produced by resteaming or adding cysteine or thioglycollic acid. Moreover, a fraction was isolated from peptone that was bacteristatic only in its oxidised state. It was therefore concluded that the redox potential of that medium was critical for the initiation of growth from small inocula.

O'Meara and Macsween (1936), examining the failure of staphylococci to grow from a small inoculum ( $<10$ cells), obtained similar results, and attributed these to the presence of copper in certain peptone preparations, which in those days were prepared in copper vessels. The copper content of the proteose peptones used in the present studies was $<11 \mu \mathrm{g}$ per $\mathrm{g}$, compared with $400-1600 \mu \mathrm{g}$ per $\mathrm{g}$ in the media of O'Meara and Macsween. In addition, two of our media containing similar amounts of copper, BBL Myosate Peptone and Difco Proteose Peptone, produced different degrees of inhibition. Other workers have found a marked reduction in the copper content of peptones since 1936 (Balch, 1942; Society for General Microbiology, 1956). Although a direct inhibitory effect of copper can probably be excluded in the present experiments, small amounts of metallic ions may perhaps catalyse the formation of colloidal sulphur from cysteine during the heating process and so affect the nutritional qualities of the medium for certain bacteria, namely Brucella, Bordetella, Mycobacterium tuberculosis and Bacillus (Schuhardt et al., 1950; Woiwod, 1954; Konowalchuk, Hinton and Reed, 1954; Rowatt, 1957; Traxler and Lankford, 1957).

Wright (1929) demonstrated that when peptone, yeast extract and serum were autoclaved at high temperatures for prolonged periods, each caused a marked inhibition of bacterial growth in culture media; $1 \%$ glucose added before heating prevented this effect. The inhibitory properties in horse serum autoclaved at $120^{\circ} \mathrm{C}$ for $30 \mathrm{~min}$. were not permanent; the heated serum, left at room temperature for 48 hours, no longer retarded the growth of pneumococci in broth.

In each instance, the inhibition we observed in peptone media was neutralised by a reducing agent, such as cysteine, thioglycollic acid or dithionite. Furthermore, Gilder and Granick (1947), who used proteose peptone broth sterilised at $121^{\circ} \mathrm{C}$ for $20 \mathrm{~min}$. in studies on the haemin requirements of Haemophilus spp., obtained growth of certain strains from small inocula only in the presence of a reducing agent, namely dithionite.

In the present study, proteose peptone agar sterilised by heating for a prolonged period at higher temperatures was inhibitory when freshly prepared, but when stored for 7 days at $4^{\circ} \mathrm{C}$ supported the growth of $H$. influenzae from small numbers of cells. This is in contrast to the experience of Dubos (1930) and O'Meara and Macsween (1936), who found that heated peptone-broth media deteriorated on standing at room temperature and that this was related to oxidation.

One difference that may invalidate a direct comparison of the present experiments with those of earlier investigators on the effect of heating is that our results were obtained on a medium containing agar. Proteose peptone and agar were sterilised separately and together at $116^{\circ} \mathrm{C}$ and $126^{\circ} \mathrm{C}$, and it was concluded that, under these conditions, the inhibition at the higher temperature was the result of an alteration of the peptone only. Even at $121^{\circ} \mathrm{C}$ for 15 min., small amounts of medium in narrow containers may be over-heated because of rapid heat penetration.

The inhibitory effect was not peculiar to one batch of Difco Proteose Peptone nor to one strain of Haemophilus. Similar results were obtained with a second batch of Difco Proteose Peptone and with encapsulated and non-encapsulated strains of $H$. influenzae, including fresh isolates and those from type-culture collections. The batches of Oxoid Proteose Peptone and BBL Myosate Peptone were not so severely affected by over-heating. Difco Proteose Peptone was initially chosen because it was the medium most commonly used in earlier nutritional work on Haemophilus and proved the most satisfactory in these studies when autoclaved at $116^{\circ} \mathrm{C}$ (Lwoff and Lwoff, 1937; Hoagland et al., 1942; Gilder 
and Granick, 1947). A feature common to the present and earlier work is that the addition of reducing agents, such as dithionite, glutathine, and Cleland's reagent, promotes growth in the presence of previously inhibitory peptone.

Reports indicate that agar may contain substances inhibitory for bacteria; for example, Ley and Mueller (1946), using methanol, extracted from commercial agar an inhibitor for Neisseria gonorrhoeae, and a water-soluble substance that adversely affected the growth of $H$. vaginalis was described by Dukes and Gardner (1961). Our results indicate that some commercial agar preparations may also be toxic for $H$. influenzae. The effect could be eliminated by washing the agar with distilled water, by allowing the powder to stand at room temperature and humidity for several weeks, or by separate sterilisation of the agar at a temperature in excess of $116^{\circ} \mathrm{C}$, that is, conditions that produce the peptone inhibitor. Unlike overheated proteose-peptone agar, the medium prepared from inhibitory agar remained inhibitory after 2 weeks' storage at $4^{\circ} \mathrm{C}$. Sodium oleate or Tween 80 effectively removed the inhibition.

The value of sodium oleate in media for Haemophilus spp. was first observed by Avery in 1918; Butler (1962) found that this substance could replace serum albumen in a semidefined medium for Haemophilus and suggested that its role may be that of a protective colloid. Albumen, starch and charcoal have a similar effect in media for the growth of other pathogens (Dubos and Davis, 1946; Casman, 1947; Mazloum and Rowley, 1955). Our previous findings with regard to the growth of certain strains of $H$. parainfluenzae (Evans and Smith, 1972) indicate that sodium oleate may be a useful additive for media used to grow members of the genus Haemophilus.

In our experience, the most suitable solid medium for identification and nutritional studies of $H$. influenzae is one based on Difco Proteose Peptone, haem and NAD, with sodium oleate and dithionite to overcome inhibition appearing in agar and peptone.

\section{SUMMARY}

Proteose-peptone agar was defective for the culture of $H$. influenzae from small inocula when sterilising temperatures exceeded $116^{\circ} \mathrm{C}$. All 23 strains tested grew poorly or not at all on the medium sterilised at temperatures of $121^{\circ} \mathrm{C}$ or more for $30 \mathrm{~min}$. The inhibition was more marked when $5 \% \mathrm{CO}_{2}$ was present during incubation. The inhibitory effect disappeared after the medium had been stored at $4^{\circ} \mathrm{C}$ for 7 days before inoculation, or could be abolished by the addition of a reducing agent such as sodium dithionite $100 \mu \mathrm{g}$ per ml.

The growth of $H$. influenzae may also be adversely affected by agar. Of three commercial agars tested, one batch of a particular brand was found to be inhibitory when used from a freshly opened bottle. Inhibition could not be demonstrated after the agar was washed or in the presence of sodium oleate $(4 \mu \mathrm{g}$ per $\mathrm{ml})$.

We wish to acknowledge with gratitude the advice given by Dr S. M. Bell and Associate Professor A. J. Wicken, and the assistance of Mr D. Croft from the Institute of Clinical Pathology and Medical Research in carrying out the copper estimations.

\section{REFERENCES}

AVERY, O. T. 1918. A selective medium for B. influenzae: oleate haemoglobin agar. $J$. Am. med. Ass., 71, 2050.

BalCh, H. H. 1942. Copper content of commercial peptones. J. Path. Bact., 54, 377.

BeAle, R. N. AND CROFT, D. 1964. The microdetermination of biological copper with oxalyldihydrazide. J. clin. Path., 17, 260.

BURNET, F. M. 1925. Hydrogen peroxide and bacterial growth. Aust. J. exp. Biol. med. Sci., 2,65 .

BUtLER, L. O. 1962. A defined medium for Haemophilus influenzae and Haemophilus parainfluenzae. J. gen. Microbiol., 27, 51. 
Casman, E. P. 1947. A noninfusion blood agar base for Neisseriae, Pneumococci and Streptococci. Am. J. clin. Path., 17, 281.

Cruickshank, R. 1965. Medical microbiology, 11th ed., London, p. 746.

DuBos, R. 1930. The bacteriostatic action of certain components of commercial peptones as affected by conditions of oxidation and reduction. J. exp. Med., 52, 331.

DuBos, R. J. AND DAvis, B. D. 1946. Factors affecting the growth of tubercle bacilli in liquid media. J. exp. Med., 83, 409.

DukEs, C. D. AND GARDNER, H. L. 1961. Identification of Haemophilus vaginalis. $J$. Bact., 81, 277.

Evans, N. M. AND Smith, D. D. 1972. The effect of the medium and source of growth factors on the satellitism test for Haemophilus species. J. med. Microbiol., 5, 509.

Gilder, H. AND Granick, S. 1947. Studies on the Hemophilus group of organisms. Quantitative aspects of growth on various porphyrin compounds. J. gen. Physiol., 31, 103.

GORDON, J. AND MCLEOD, J. W. 1926. Inhibition of bacterial growth by some amino-acids and its bearing on the use of tryptic digests as culture media. J. Path. Bact., 29, 13.

Hoagland, C. L., Ward, S. M., Gilder, H. and Shank, R. E. 1942. Studies on the nutrition of Haemophilus influenzae. I. The relationship between the utilization of coenzyme and hemin and the reduction of nitrate. J. exp. Med., 76, 241.

KonowalchuK, J., Hinton, N. A. AND REED, G. B. 1954. Antibacterial action of a reaction product of cysteine and iron. 1. Development of the substance in media for Mycobacterium tuberculosis. Can. J. Microbiol., 1, 175.

LeY, H. L. AND MuelleR, J. H. 1946. On the isolation from agar of an inhibitor for Neisseria gonorrhoeae. J. Bact., 52, 453.

Lwoff, A. AND Lwoff, M. 1937. Studies on codehydrogenases. I. Nature of growth factor "V". Proc. R. Soc. B., 122, 352.

MaZloum, H. A. AND Rowley, D. 1955. The growth requirements of Haemophilus pertussis on solid media. J. Path. Bact., 70, 439.

NiEMAN, C. 1954. Influence of trace amounts of fatty acids on the growth of microorganisms. Bact. Rev., 18, 147.

O'Meara, R. A. Q. AND Macsween, J. C. 1936. The failure of Staphylococcus to grow from small inocula in routine laboratory media. J. Path. Bact., 43, 373.

Proom, H., Worwod, A. J., Barnes, J. M. AND Orbell, W. G. 1950. A growth-inhibitory effect on Shigella dysenteriae which occurs with some batches of nutrient agar and is associated with the production of peroxide. J. gen. Microbiol., 4, 270.

RowATt, E. 1957. The growth of Bordetella pertussis: a review. J.gen. Microbiol., 17, 297.

SchuHardt, V. T., Rode, L. J., OGlesby, G. AND Lankford, C. E. 1950. The development of peptone toxicity for brucellae with aging and the correlation of this toxicity with the probable oxidation of cystine. J. Bact., 60,655 .

SOCIETY FOR GENERAL MICROBIOLOGY 1956. Constituents of bacteriological culture media. Special report, edited by G. Sykes, Cambridge, p. 2.

Steers, E., Foltz, E. L. AND Graves, B. S. 1959. An inocula replicating apparatus for routine testing of bacterial susceptibility to antibiotics. Antibiotics Chemother, 9, 307.

Traxler, R. W. AND LANKFord, C. E. 1957. Observations on cystine degradation and bacteriotoxicity of peptones. Appl. Microbiol., 5, 70.

WorwoD, A. J. 1954. The inhibition of bacterial growth by colloidal heavy-metal sulphides and by colloidal sulphur. J. gen. Microbiol., 10, 509.

WRIGHT, H. D. 1929. The effect of certain factors upon the growth of the pneumococcus. J. Path. Bact., 32, 203. 